\title{
A PROGRESSIVE SHUTTLE RUN TEST TO ESTIMATE MAXIMAL OXYGEN UPTAKE
}

\author{
R. RAMSBOTTOM, J. BREWER and C. WILLIAMS \\ Department of Physical Education and Sports Science, University of Technology, Loughborough, Leicestershire LE11 3 TU
}

\section{ABSTRACT}

The purpose of the present study was to examine the validity of using a $20 \mathrm{~m}$ progressive shuttle run test to estimate maximal oxygen uptake. Running ability was described as the final level attained on the shuttle run test and as time on a $5 \mathrm{~km}$ run. Maximal oxygen uptake $\left(\mathrm{VO}_{2} \mathrm{max}\right)$ was determined directly for seventy-four volunteers (36 men, 38 women) who also completed the shuttle run test. Maximal oxygen uptake values were $58.5 \pm 7.0$ and $47.4 \pm 6.1 \mathrm{ml}^{\circ} \mathrm{kg}^{-1} . \mathrm{min}^{-1}$ for the men and women respectively (mean $\pm S D, P<0.01$ ). The levels attained on the shuttle run test were $12.6 \pm 1.5$ (men) and $9.6 \pm 1.8$ (women; $\mathrm{P}<0.01$ ). The correlation between $\mathrm{VO}_{2}$ max and shuttle level was 0.92 . The correlation between $\mathrm{VO}_{2}$ max and the $5 \mathrm{~km}$ run was -0.94 and the correlation between both field tests was -0.96 . The results of this study suggest that a progressive shuttle run test provides a valid estimate of $\mathrm{VO}_{2}$ max and indicates $5 \mathrm{~km}$ running potential in active men and women.

Key words: Maximal oxygen uptake, Shuttle run test, $5 \mathrm{~km}$ run

\section{INTRODUCTION}

Elite distance runners are characterised by high maximal oxygen uptake values $\left(\mathrm{VO}_{2} \max \right)$ (Saltin and Åstrand, 1967; Svedenhag and Sjödin, 1984) and good performance times in distance races (Costill et al, 1973; Farrell et al, 1979). Maximal oxygen uptake reflects the ability of the cardiovascular system to deliver oxygen to the working muscles. Thus individuals with high $\mathrm{VO}_{2}$ max values have been regarded traditionally as possessing "endurance fitness" or "cardiorespiratory fitness". Although it is a useful criterion of the overall capacity of the individual to perform exercise aerobically (Rowell et al, 1964) the direct determination of $\mathrm{VO}_{2}$ max demands sophisticated instrumentation, laboratory time and trained personnel. Consequently, such measurements are not practicable for large groups of individuals. Therefore attempts have been made to develop simple field tests to provide an estimate of $\mathrm{VO}_{2}$ max. Such tests require the subject either to cover as much distance as possible in a set time (Cooper, 1970) or to cover a set distance in the fastest time possible (Getchell et al, 1977; Ramsbottom et al, 1987). These field tests are maximal from the onset and require well motivated subjects with some knowledge of pace judgement and an understanding of the test requirements (Shephard, 1984).

With the continued interest in running for health and well-being the interest in field tests has undergone reevaluation (Burke, 1976; Johnson et al, 1979). A recent development in field testing has been the introduction of a continuous multi-stage track test (Léger and Boucher, 1980) and maximal multi-stage $20 \mathrm{~m}$ shuttle run test (Léger and Lambert, 1982) to predict $\mathrm{VO}_{2}$ max. These tests are progressive in nature but the subject is still required to exercise maximally at the end of the test. During the development of each of these tests expired air was collected during the recovery period and $\mathrm{VO}_{2}$ max determined by back extrapolation. The correlation between $\mathrm{VO}_{2}$ max determined by this retro-extrapolation method was $r=0.84(n=91)$ with a standard error of the estimate of $5.4 \mathrm{ml} . \mathrm{kg}^{-1} \cdot \mathrm{min}^{-1}$ (Léger and Lambert, 1982). The purpose of the present study was to re-examine the validity of using a $20 \mathrm{~m}$ progressive shuttle run test (20 m PST) (Eurofit Provisional Handbook,

Address for correspondence:

R. Ramsbottom, BSc, MPhil

Department of Physical Education and Sports Science

University of Technology

Loughborough,

Leicestershire

LE11 3TU
1983) to estimate $\mathrm{VO}_{2}$ max. A $5 \mathrm{~km}$ performance test was included to allow comparison with previous work relating performance on an outdoor track test to directly determined $\mathrm{VO}_{2} \max$ (Ramsbottom et al, 1987).

\section{METHODS}

Seventy-four volunteers (36 men, 38 women, age range 19 to $36 \mathrm{yr}$ ) participated in the present study. They performed, in random order, an uphill treadmill test to determine $\mathrm{VO}_{2}$ max directly, a $20 \mathrm{~m}$ PST and a $5 \mathrm{~km}$ time trial. Before the start of each test a minimum warm-up period of five minutes was allowed. An interval of 3 days elapsed between each test.

All subjects were familiarised with treadmill running before performing an uphill treadmill run for determination of $\mathrm{VO}_{2}$ max (modified after Taylor et al, 1955). Treadmill running speeds were such that the subject became exhausted in 7 to $10 \mathrm{~min}$. The inclination of the treadmill (Woodway ELG2) increased $2.5 \%$ every three minutes from an initial $3.5 \%$. One minute samples of expired air were collected at the end of each three-minute period for the determination of oxygen consumption and carbon dioxide production (Williams and Nute, 1983). A final collection of expired air was made when the subject indicated that they could continue for only one more minute. Heart rate was monitored on an oscilloscope (Rigel Research Ltd.) using four chest electrodes. A short-range telemetry system (Sports Tester PE3000; Polar Electro, Finland) was used to record heart rate during both the $20 \mathrm{~m}$ PST and the $5 \mathrm{~km}$ time trial. The maximum heart rate was defined as the highest recorded heart rate during the laboratory determination of $\mathrm{VO}_{2}$ max.

The $20 \mathrm{~m}$ progressive shuttle run test performed by the subjects in the present study was identical with that described in the Eurofit Provisional Handbook (Strasbourg, 1983). Briefly, this consisted of shuttle running between two markers placed $20 \mathrm{~m}$ apart at increasing fast speeds. The test took place on a wooden gymnasium surface and accurate timing of running pace was provided by a BBC microcomputer. The running speed increased $0.14 \mathrm{~m} . \mathrm{s}^{-1}$ each minute, this change in running speed was described as a change in level. Subjects ran in groups of no more than four to stimulate competition and ensure a maximal effort. The $5 \mathbf{~ k m}$ time trial took place on the University athletic track under favourable environmental conditions. The subjects were well-motivated and were encouraged to run their fastest $5 \mathrm{~km}$ time. Performance time was measured using the short range telemetry system referred to previously and 
confirmed using digital stop-watches. When possible three to four subjects ran the $5 \mathrm{~km}$ time trial at the same time to encourage competition.

The significance of differences between means was determined using Student's t-test and the strength of the relationships was described using the Pearson product moment correlation coefficient.

\section{RESULTS}

The physical characteristics of the volunteers in this study were (mean \pm SD) height $176.0 \pm 8.1 \mathrm{~cm}$ (men) and $168.1 \pm$ $6.2 \mathrm{~cm}$ (women, $P<0.01$ ); weight $70.9 \pm 7.7 \mathrm{~kg}$ (men) and $64.1 \pm 9.5 \mathrm{~kg}$ (women, $P<0.01$ ). Their physiological and performance characteristics are shown in Table I. The typical heart rate response of a subject during the laboratory determination of $\mathrm{VO}_{2} \max$ (HR max, 197 b.min-1), the $20 \mathrm{~m}$ PST and the $5 \mathrm{~km}$ time trial is shown in Fig. 1. During the $5 \mathrm{~km}$ time trial the highest heart rates were attained during the final $200 \mathrm{~m}$, i.e. $187 \pm 9$ b. $\mathrm{min}^{-1}$ (men) and $192 \pm 9$ b. $\mathrm{min}^{-1}$ (women, ns) (Fig. 2). Shuttle run performance has been described as the final running speed (Léger and Lambert, 1982) or $20 \mathrm{~m}$ shuttle attained (Paliczka et al, 1987; Ramsbottom et al, 1988). In the present study correlations between $\mathrm{VO}_{2}$ max and final shuttle attained and $\mathrm{VO}_{2} \max$ and final level attained were very similar (Table II). For convenience, therefore, performance was described as the final level attained (Fig. 3). Maximal oxygen uptake values were also predicted from the final running speed attained in the $20 \mathrm{~m}$ PST using the regression equation provided by Léger and Lambert (1982). Final running speed was related to the directly determined $\mathrm{VO}_{2}$ max values in the present study $[r=0.82$ (men), $r=0.85$ (women) and $r=0.90$ (men and women)].

\section{TABLE \|}

Pearson product moment correlations between maximal oxygen uptake and running performance characteristics of the male and female subjects

\begin{tabular}{lcccc}
\hline Performance characteristics & Men & Women & Men and women \\
\hline PST level (no.) & $r=0.82$ & $r=0.89$ & $r=0.92$ \\
PST shuttle (no.) & $r=0.83$ & $r=0.93$ & $r=0.93$ \\
5 km time (min) & $r=-0.76^{*}$ & $r=-0.83$ & $r=-0.94$ \\
\hline
\end{tabular}

* significant at $P<0.05$, all other correlations $P<0.01$

PST $=$ Progressive Shuttle run Test

\section{DISCUSSION}

The year-long period devoted to the present study enabled the recruitment of a large number of men and women who displayed a wide range of $\mathrm{VO}_{2}$ max values. All subjects were young adults involved in physical training on a regular basis. The correlation between directly determined $\mathrm{VO}_{2}$ max values and a $5 \mathrm{~km}$ time trial has been reported as $r=0.89$ (SEE $3.7 \mathrm{ml}^{\mathrm{k}} \mathrm{kg}^{-1} \cdot \mathrm{min}^{-1}$ ) for such groups (Ramsbottom et al, 1987). This compares with a correlation of $r=0.92$ (SEE $3.5 \mathrm{ml} \cdot \mathrm{kg}^{-1} \cdot \mathrm{min}^{-1}$ ) between directly determined $\mathrm{VO}_{2}$ max values and a $20 \mathrm{~m}$ PST in the present study. The variance unaccounted for by $\mathrm{VO}_{2}$ max may be attributable to differences in running economy (Conley and Krahenbuhl, 1980), relative running economy (Costill et al, 1973; Sjödin and Svedenhag, 1985; Ramsbottom et al, 1987), the rate of onset of plasma or blood lactate accumulation (Farrell et al, 1979; Sjödin and Jacobs, 1981) or the training status of the individual (Londeree and Ames, 1975; Hurley et al, 1984).

Because of the linear relationship between oxygen consumption and running velocity (Mayhew, 1977; Hagan et al, 1980) it is not surprising that strong correlations exist between running performance ( $20 \mathrm{~m}$ PST, $5 \mathrm{~km}$ time trial) and $\mathrm{VO}_{2}$ max when individuals with a large range of $\mathrm{VO}_{2} \max$ values are represented. Those individuals who attained high levels on the $20 \mathrm{~m}$ PST also tended to run the faster $5 \mathrm{~km}$ track times. Similar relationships between $\mathrm{VO}_{2}$ max, a multi-stage shuttle run test and running performance (10 $\mathrm{km}$ race times) in a small sample of adult men have been reported recently by Paliczka and co-workers (1987).

As maximal oxygen uptake is approached during uphill treadmill running the heart rate plateaus in parallel with the $\mathrm{VO}_{2}$, reflecting the central limitation to any further increase in oxygen transport. During the shuttle run test, and especially in the latter stages, the heart rate response was curvilinear, suggesting that the one-minute interval between shuttle levels, did not allow steady state conditions to be attained (Maksud et al, 1971; Hagan et al, 1980). Both men and women were able to maintain approximately $97 \%$ of their laboratory-defined maximal heart rate during the $5 \mathrm{~km}$ time trial which is consistent with near maximum cardiac output. Because oxygen consumption parallels cardiac output, these results tend to support the suggestion that active men and women are able to tolerate approximately $90 \% \mathrm{VO}_{2}$ max during a maximal effort over $5 \mathrm{~km}$ (Ramsbottom et al, 1987). Indeed the heart rate values, determined during laboratory and field tests, reflect the

TABLE I

Physiological and performance characteristics of the male $(n=36)$ and fomale $(n=38)$ subjects (mean \pm SD)

\begin{tabular}{|c|c|c|c|c|c|c|}
\hline & \multirow{2}{*}{$\begin{array}{c}\text { Max. Oxygen Uptake } \\
\text { VO }_{2} \max \\
\left(m l . k^{-1} \cdot \min ^{-1}\right)\end{array}$} & \multicolumn{3}{|c|}{$20 \mathrm{~m}$ Progressive Shuttle Run Test PST } & \multicolumn{2}{|c|}{$5 \mathrm{~km}$ run } \\
\hline & & $\begin{array}{l}\text { Level } \\
\text { (no.) }\end{array}$ & $\begin{array}{c}\text { Shuttle } \\
\text { (no.) }\end{array}$ & $\begin{array}{c}\text { HR } \\
\left.\text { (b. } \min ^{-1}\right)\end{array}$ & $\begin{array}{l}\text { Time } \\
\text { (min) }\end{array}$ & $\begin{array}{c}\text { HR } \\
\left.\text { (b. } \min ^{-1}\right)\end{array}$ \\
\hline \multicolumn{7}{|l|}{ Men } \\
\hline $\mathbf{n}$ & 36 & 36 & 36 & 34 & 10 & 10 \\
\hline Mean & 58.5 & 12.6 & 121 & 192 & 18.40 & 187 \\
\hline SD & 7.0 & 1.5 & 17 & 9 & 2.47 & 9 \\
\hline Range & 45.9-77.8 & $10-15$ & $92-150$ & $175-220$ & $14.83-21.90$ & $176-206$ \\
\hline \multicolumn{7}{|c|}{ Women } \\
\hline $\mathbf{n}$ & 38 & 38 & 38 & 36 & 16 & 13 \\
\hline Mean & 47.4* & $9.6^{*}$ & $85^{*}$ & 194 & $26.90^{*}$ & 192 \\
\hline SD & 6.1 & 1.8 & 20 & 10 & 2.67 & 9 \\
\hline Range & $39.6-67.4$ & $7-14$ & $53-144$ & $169-214$ & $22.90-32.07$ & $172-215$ \\
\hline
\end{tabular}

*significantly different between men and women $P<0.01$ 

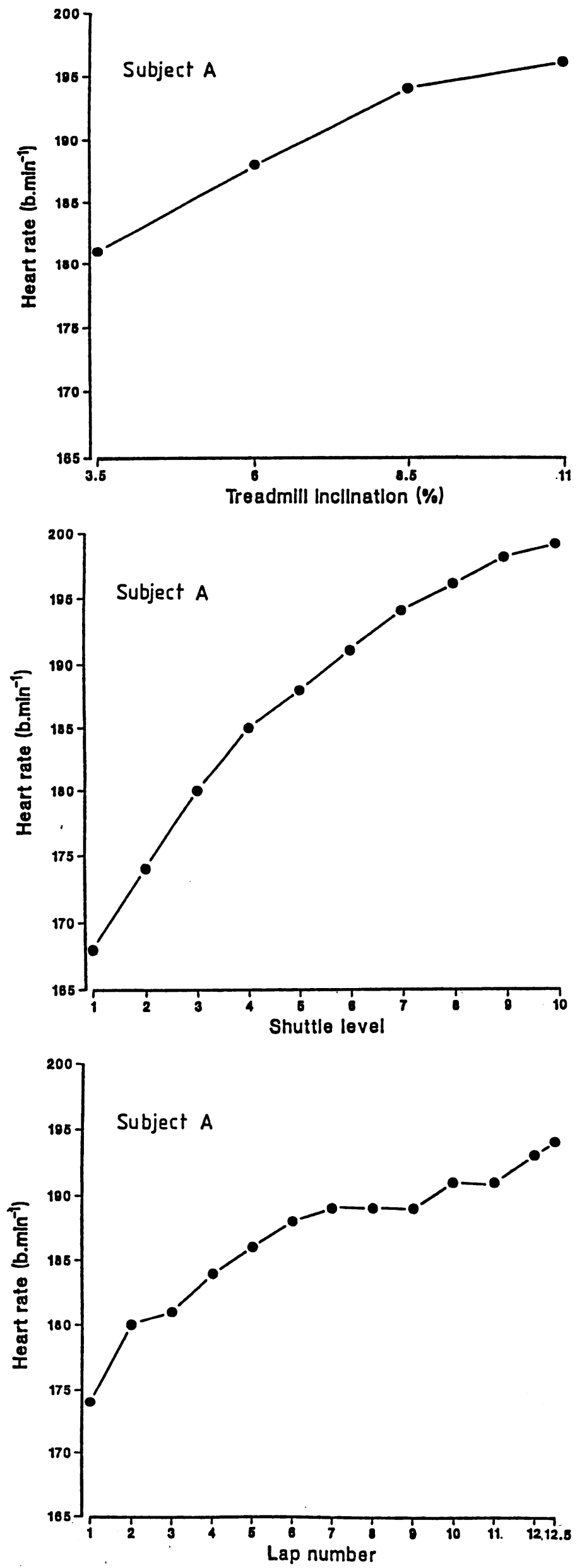

Fig. 1: Heart rate during the maximal running tests for a typical subject.

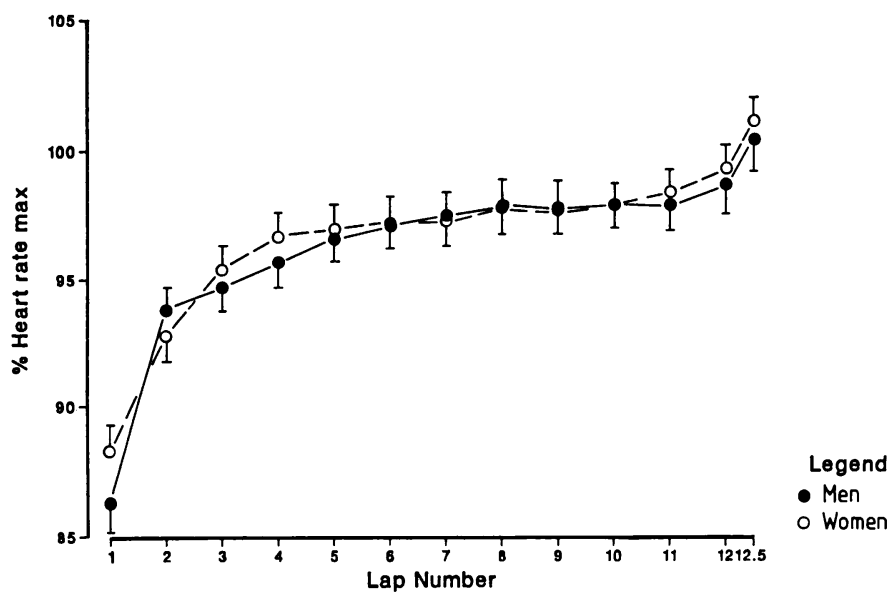

Fig. 2: Percentage of heart rate max and $5 \mathrm{~km}$ track performance (lap number) for men $(n=10)$ and women $(n=13)$.

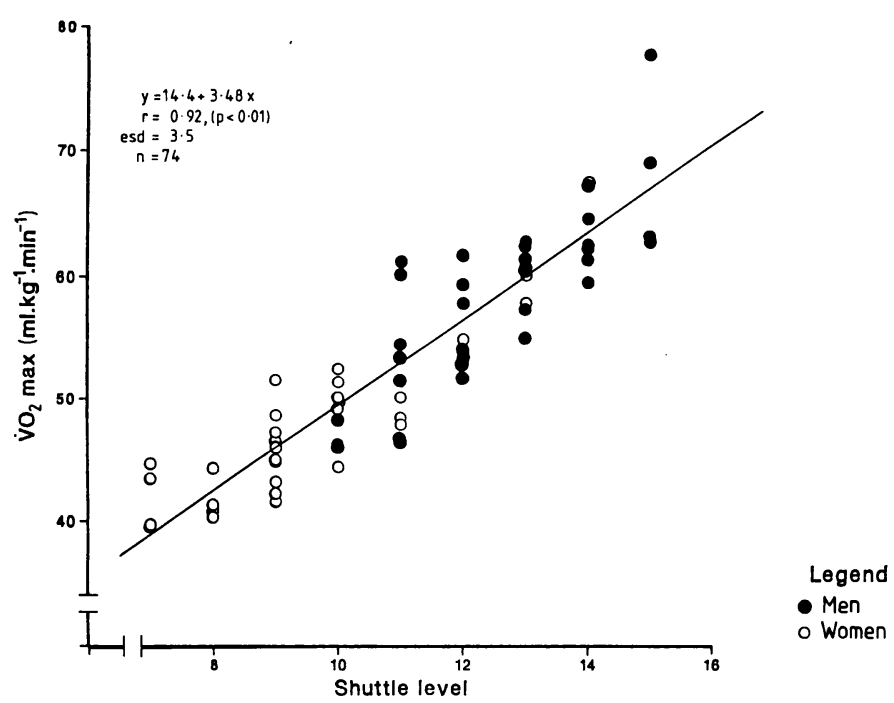

Fig. 3: The relationship between $\mathrm{VO}_{2}$ max and $20 \mathrm{~m}$ PST performance for men $(n=36)$ and women $(n=38)$.

dynamic nature of these tests and the acute functional adjustments required to meet these demands.

Thus the results of two field tests $(5 \mathrm{~km}$ time trial, $20 \mathrm{~m}$ PST) have been reported by this laboratory to provide estimates of $\mathrm{VO}_{2}$ max for members of an active adult population. While both indirect tests yield similar strong correlations and estimated standard deviations about the regression-line between directly determined $\mathrm{VO}_{2}$ max values and performance, the shuttle run test may possess certain advantages over a $5 \mathrm{~km}$ time trial. These include constant environmental conditions, a graded physiological response and the absence of a need for judgement of pace. The advantages justify use of the test in the exploration of the physiological and metabolic responses during exercise, not only of a young active population, but also other age groups or in monitoring the return of functional capacity in post-operative patients.

\section{SUMMARY}

These results show that maximal oxygen uptake values can be predicted from the level attained on a $20 \mathrm{~m}$ progressive shuttle run test $(r=0.92 ; P<0.01)$ with an estimated standard deviation about the regression line of $3.5 \mathrm{ml}^{\mathrm{k}} \mathrm{kg}^{-1} \cdot \mathrm{min}^{-1}$. The results obtained on this test may also provide an indication of endurance running ability in active men and women. 
TABLE III

Table of predicted maximal oxygen uptake values for the progressive shuttle run test. Dept. of PE \& Sports Science, Loughborough University, 1988

\begin{tabular}{|c|c|c|c|c|c|}
\hline Level & Shuttle & $\begin{array}{l}\text { LUT Predicted } \\
\dot{\mathrm{VO}}_{2} \max \end{array}$ & Level & Shuttle & $\begin{array}{l}\text { LUT Predicted } \\
\mathrm{VO}_{2} \max \end{array}$ \\
\hline 4 & 2 & 26.8 & 14 & 2 & 61.1 \\
\hline 4 & 4 & 27.6 & 14 & 4 & 61.7 \\
\hline 4 & 6 & 28.3 & 14 & 6 & 62.2 \\
\hline \multirow[t]{2}{*}{4} & 9 & 29.5 & 14 & 8 & 62.7 \\
\hline & & & 14 & 10 & 63.2 \\
\hline 5 & 2 & 30.2 & 14 & 13 & 64.0 \\
\hline 5 & 4 & 31.0 & & & \\
\hline 5 & 6 & 31.8 & 15 & 2 & 64.6 \\
\hline \multirow[t]{2}{*}{5} & 9 & 32.9 & 15 & 4 & 65.1 \\
\hline & & & 15 & 6 & 65.6 \\
\hline 6 & 2 & 33.6 & 15 & 8 & 66.2 \\
\hline 6 & 4 & 34.3 & 15 & 10 & 66.7 \\
\hline 6 & 6 & 35.0 & 15 & 13 & 67.5 \\
\hline 6 & 8 & 35.7 & & & \\
\hline \multirow[t]{2}{*}{6} & 10 & 36.4 & 16 & 2 & 68.0 \\
\hline & & & 16 & 4 & 68.5 \\
\hline 7 & 2 & 37.1 & 16 & 6 & 69.0 \\
\hline 7 & 4 & 37.8 & 16 & 8 & 69.5 \\
\hline 7 & 6 & 38.5 & 16 & 10 & 69.9 \\
\hline 7 & 8 & 39.2 & 16 & 12 & 70.5 \\
\hline 7 & 10 & 39.9 & 16 & 14 & 70.9 \\
\hline 8 & 2 & 40.5 & 17 & 2 & 71.4 \\
\hline 8 & 4 & 41.1 & 17 & 4 & 71.9 \\
\hline 8 & 6 & 41.8 & 17 & 6 & 72.4 \\
\hline 8 & 8 & 42.4 & 17 & 8 & 72.9 \\
\hline \multirow[t]{2}{*}{8} & 11 & 43.3 & 17 & 10 & 73.4 \\
\hline & & & 17 & 12 & 73.9 \\
\hline 9 & 2 & 43.9 & 17 & 14 & 74.4 \\
\hline 9 & 4 & 44.5 & & & \\
\hline 9 & 6 & 45.2 & 18 & 2 & 74.8 \\
\hline 9 & 8 & 45.8 & 18 & 4 & 75.3 \\
\hline \multirow[t]{2}{*}{9} & 11 & 46.8 & 18 & 6 & 75.8 \\
\hline & & & 18 & 8 & 76.2 \\
\hline 10 & 2 & 47.4 & 18 & 10 & 76.7 \\
\hline 10 & 4 & 48.0 & 18 & 12 & 77.2 \\
\hline 10 & 6 & 48.7 & 18 & 15 & 77.9 \\
\hline 10 & 8 & 49.3 & & & \\
\hline \multirow[t]{2}{*}{10} & 11 & 50.2 & 19 & 2 & 78.3 \\
\hline & & & 19 & 4 & 78.8 \\
\hline 11 & 2 & 50.8 & 19 & 6 & 79.2 \\
\hline 11 & 4 & 51.4 & 19 & 8 & 79.7 \\
\hline 11 & 6 & 51.9 & 19 & 10 & 80.2 \\
\hline 11 & 8 & 52.5 & 19 & 12 & 80.6 \\
\hline 11 & 10 & 53.1 & 19 & 15 & 81.3 \\
\hline \multirow[t]{2}{*}{11} & 12 & 53.7 & & & \\
\hline & & & 20 & 2 & 81.8 \\
\hline 12 & 2 & 54.3 & 20 & 4 & 82.2 \\
\hline 12 & 4 & 54.8 & 20 & 6 & 82.6 \\
\hline 12 & 6 & 55.4 & 20 & 8 & 83.0 \\
\hline 12 & 8 & 56.0 & 20 & 10 & 83.5 \\
\hline 12 & 10 & 56.5 & 20 & 12 & 83.9 \\
\hline 12 & 12 & 57.1 & 20 & 16 & 84.8 \\
\hline 13 & 2 & 57.6 & & & \\
\hline 13 & 4 & 58.2 & & & \\
\hline 13 & 6 & 58.7 & & & \\
\hline $13^{\prime}$ & 8 & 59.3 & & & \\
\hline 13 & 10 & 59.8 & & & \\
\hline 13 & 13 & 60.6 & & & \\
\hline
\end{tabular}

\section{ACKNOWLEDGEMENTS}

We gratefully acknowledge the contribution of Dr. Tytler (Department of Biological Sciences, University of Stirling) for the BBC microcomputer program for the timing of the $20 \mathrm{~m}$ PST. From the results obtained in the present study a table of $\mathrm{VO}_{2}$ max values, together with the appropriate shuttle run performance, was prepared for use within the Department of Physical Education and Sports Science (University of Loughborough) (Table III). This table, together with a pre-recorded cassette tape giving instructions for performing the $20 \mathrm{~m}$ progressive shuttle run test are available from National Coaching Foundation, 4 College Close, Beckett Park, LEEDS LS6 30H.

\section{References}

Burke, E. J., 1976 "Validity of Selected Laboratory and Field Tests of Working Capacity". Research Quarterly 47: 95-102.

Conley, D. L. and Krahenbuhl, G. S., 1980 "Running economy and distance running performance of highly trained athletes". Medicine and Science in Sports 12 (5): 357-360.

Cooper, K. H., 1970. The New Aerobics. Bantam Books Inc., New York.

Costill, D. L., Thomason, H. and Roberts, E., 1973 "Fractional utilization of the aerobic capacity during distance running". Medicine and Science in Sports 5 (4): 248-252.

Eurofit Provisional Handbook (Strasbourg, 1983). Testing Physical Fitness. Pub. HMSO, London.

Farrell, P. A., Wilmore, J. H., Coyle, E. F., Billing, J. E. and Costill, D. L., 1979 "Plasma lactate accumulation and distance running performance". Medicine and Science in Sports 11 (4): 338-344.

Getchell, L. H., Kirkendall, D. and Robbins, G., 1977 "Prediction of Maximal Oxygen Uptake in Young Adult Women Joggers". Research Quarterly 48: 61-67.

Hagan, R. D., Strathman, T., Strathman, L. and Gettman, L. R., 1980 "Oxygen uptake and energy expenditure during horizontal treadmill running". Journal of Applied Physiology: Respiration, Environmental, Exercise Physiology 49 (4): 571-575.

Hurley, B. F., Hagberg, J. M., Allen, W. K., Seals, D. R., Young, J. C., Cuddihee, R. W. and Holloszy, J. O., 1984 "Effect of training on blood lactate levels during submaximal exercise". Journal of Applied Physiology 56: 1260-1264.

Johnson, D. J., Oliver, R. A. and Terry, J. W., 1979 "Regression equation for prediction of performance in the twelve minute run walk test". Journal of Sports Medicine and Physical Fitness 19: 165-170.

Léger, L. and Boucher, R., 1980 "An Indirect Continuous Running Multistage Field Test: The Université de Montreal Track Test". Canadian Journal of Applied Sports Sciences 5: 77-84.

Léger, L. A. and Lambert, J., 1982 "A Maximal Multistage 20-m Shuttle Run Test to Predict $\mathrm{VO}_{2}$ max". European Journal of Applied Physiology 49: 1-12.

Londeree, B. R. and Ames, S. A., 1975 "Maximal Steady State Versus State of Conditioning". European Journal of Applied Physiology 34: 269-273.

Maksud, M. G., Coutts, K. D. and Hamilton, L. H., 1971 "Time course of heart rate, ventilation and $\mathrm{VO}_{2}$ during laboratory and field exercise". Journal of Applied Physiology 30 (4): 536-539.

Mayhew, J. L., 1977 "Oxygen cost and energy expenditure of running in trained runners". British Journal of Sports Medicine 11 (3): 116-121.

Paliczka, V. J., Nichols, A. K. and Boreham, C. A. G., 1987 "A Multistage Shuttle Run as a Predictor of Running Performance and Maximal Oxygen Uptake in Adults". British Journal of Sports Medicine 21 (4): 163-164.

Ramsbottom, R., Brewer, J. and Williams, C., 1988 "An examination of the maximal multistage shuttle run test as a predictor of $\mathrm{VO}_{2}$ max in active female subjects". Journal of Sports Sciences 6: 165A.

Ramsbottom, R., Nute, M. L. G. and Williams, C., 1987 "Determinants of 5 Kilometre Performance in Active Men and Women". British Journal of Sports Medicine 21 (2): 9-13.

Rowell, L. B., Taylor, H. L. and Wang, Y., 1964 "Limitations to prediction of maximal oxygen intake". Journal of Applied Physiology 19 (5): 919-927.

Saltin, B. and Astrand, P. O., 1967 "Maximal Oxygen Uptake in Athletes". Journal of Applied Physiology 23: 353-358.

Shephard, R. J., 1984 "Tests of Maximum Oxygen Intake: A Critical Review". Sports Medicine 1: 99-124.

Sjödin, B. and Jacobs, I., 1981 "Onset of Blood Lactate Accumulation and Marathon Running Performance". International Journal of Sports Medicine 2: 23-26.

Sjödin, B. and Svedenhag, J., 1985 "Applied Physiology of Marathon Running". Sports Medicine 2: 83-99.

Svedenhag, J. and Sjödin, B., 1984 "Maximal and submaximal oxygen uptakes and blood lactate levels in elite male middle- and long-distance runners". International Journal of Sports Medicine 5: 255-261.

Taylor, H.L., Buskirk, E. and Henschel, A., 1955 "Maximal Oxygen Intake as an Objective Measure of Cardiorespiratory Peformance". Journal of Applied Physiology 8: 73-80.

Williams, C. and Nute, M. L. G., 1983 "Some Physiological Demands of a HalfMarathon Race on Recreational Runners". British Journal of Sports Medicine 17: 152-161. 